\title{
PANDANGAN HINDU TERHADAP PEMIKIRAN \\ KEFILSAFATAN PYTHAGORAS
}

Oleh :

I PUTU AGUS ARYATNAYA GIRI

\begin{abstract}
ABSTRAK
Ada sebuah kemiripan konsep pemikiran kefilsafatan antara Pythagoras dan Hindu. sebut saja yang pertama bahwa Pythagoras percaya akan adanya Jiwa dan perpindahan jiwa dari makhluk yang sekarang kepada makhluk yang akan datang. Apabila seseorang meninggal, jiwanya kembali lagi kedunia, masuk kedalam badan salah satu hewan. Hindu sendiri mengenal ajaran tersebut sebagai Punarbhawa atau Samsara yang merupakan bagian dari Panca Sraddha. Di sisi lain, Pythagoras juga menyatakan bahwa untuk mencapai hidup murni, haruslah orang memantangkan makan daging dan kacang. Dengan kepercayaannya itu Pythagoras menjadi penganjur vegetarisme, yang hanya memakan sayur mayur dan buah-buahan saja, yang dalam Hindu termasuk dalam ajaran ahimsa.
\end{abstract}

\section{ABSTRACT}

There is a similarity to the concept of philosophical thinking between Pythagoras and Hinduism. just call the first that Pythagoras believed in the existence of the Soul and the transfer of souls from the present being to the creatures to come. When someone dies, his soul returns to the world, enters the body of one animal. Hindus themselves know these teachings as Punarbhawa or Samsara which are part of Panca Sraddha. On the other hand, Pythagoras also stated that in order to achieve a pure life, one must eat meat and beans. With his belief, Pythagoras became an advocate of vegetarianism, which only ate vegetables and fruits, which in Hinduism were included in the teachings of ahimsa.

\section{PENDAHULUAN}

Menurut catatan sejarah, filsafat bermula di Yunani. Bangsa Yunani mulai mempergunakan akal ketika mempertanyakan mitos yang berkembang di masyarakat sekitar abad VI SM. Perkembangan pemikiran ini menandai usaha manusia untuk mempergunakan akal dalam memahami segala sesuatu. Pemikiran Yunani sebagai embrio filsafat Barat berkembang menjadi titik tolak pemikiran barat abad pertengahan, modern dan masa berikutnya. Disamping menempatkan filsafat sebagai sumber pengetahuan, Barat juga 
menjadikan agama sebagai pedoman hidup, meskipun memang harus diakui bahwa hubungan filsafat dan agama mengalami pasang surut. Pada abad pertengahan misalnya dunia barat didominasi oleh dogmatisme gereja (agama), tetapi abad modern seakan terjadi pembalasan terhadap agama. Peran agama di masa modern digantikan ilmu-ilmu positif. Akibatnya, Barat mengalami kekeringan spiritualisme. Namun selanjutnya, Barat kembali melirik kepada peranan agama agar kehidupan mereka kembali memiliki makna.

Agama Hindu adalah agama yang tidak bisa dilepaskan dari sistem filsafat. Ini terbukti dari adanya Tri Kerangka Dasar Agama Hindu yang terdiri dari Tattwa, Susila, dan Upacara. Tattwa itu sendiri kadangkala diidentikan atau sering disebut dengan filsafat. Mungkin yang dimaksudkan adalah Tattwa yang terdiri dari unsur Panca Sradha itu memuat konsef filosofis yang kesemuanya merupakan kebenaran paling hakiki. Bila dihubungkan, Tattwa itu adalah hakikat kebenaran dan filsafat itu sendiri adalah cara untuk mencari kebenaran. Filsafat yang sering disebut dengan Mother Of Science memang mampu membawa kehidupan manusia menuju dunia yang sarat akan kebijaksanaan. Karena manusia diajak untuk berfikir kritis tentang sebab akibat yang ada di dunia ini bahkan pencarian spiritual manusia pun tak terlepas dari pengaruh filsafat. Agama adalah kepercayaan kepada Tuhan serta segala sesuatu yang bersangkut paut dengan itu. Dengan Agama hidup manusia menjadi lebih aman karena agama membekali manusia dengan iman tertentu yang menambatkan ia pada suatu tempat berpegang yang kokoh. Pythagoras yang selama ini dikenal sebagai penggagas filsafat bilangan, ternyata juga memiliki pemikiran kefilsafatan lain yang menarik untuk dibahas, karena memiliki sisi kemiripan dengan konsep ajaran Hindu utamanya tentang eksistensi jiwa dan perpindahannya dari satu makhluk ke makhluk yang lainnya melalui proses kelahiran berulang-ulang (Punarbhawa) serta ajaran Ahimsa utamanya tentang anjuran untuk menjadi penganut vegetarian guna mewujudkan kesehatan jasmani dan meningkatkan kemurnian jiwa

\section{DEFINISI FILSAFAT}

Istilah filsafat dalam bahasa Yunani "Philosophia" yang dalam perkembangan berikutnya dikenal dalam bahasa lain yaitu : Philosophie (Jerman, Belanda, dan Perancis), Philosophy (Inggris), Philosophia (Latin) dan falsafah (Arab). Pengertian filsafat berdasarkan asal kata tersebut di atas akan menghasilkan pengertian yang berbeda-beda dalam makna yang tidak hakiki, jadi perbedaan tersebut hanya bersifat gradasi saja. Aktivitas akal budi yang dilakukan oleh filsuf yang berupa philosophein memiliki dua unsur pokok, yaitu : pertama philen dan sophos, kedua philos dan sophia. Kedua kelompok upaya mencari akar pengertian istilah tersebut dapat diurai sebagai berikut. Pertama unsur philen dan sophos, "philen" berarti mencintai, dan "sophos" berarti bijaksana. Istilah philosophia dengan akar kata philien dan sophos yang berarti mencintai akan hal-hal yang bersifat bijaksana. Istilah philosophia dengan akar kata philos dan Sophia berarti kawan kebijaksanaan. Philosophie menurut arti katanya adalah cinta akan kebijaksanaan dan berusaha untuk memilikinya (Sudarsono, 2001:10).

Pythagoras memberikan definisi filsafat sebagai love of wisdom. Menurutnya manusia 
yang paling tinggi nilainya adalah manusia pecinta kebijakan (lover of wisdom), sedangkan yang dimaksudkan dengan wisdom adalah kegiatan melakukan perenungan tentang Tuhan. Pythagoras sendiri menganggap dirinya seorang philosophos (pecinta kebijakan), baginya kebijakan yang sesungguhnya hanyalah dimiliki semata-mata oleh Tuhan (Susanto, 2013: 2).

Mustansyir dan Munir (2001:3) dalam Banasuru (2012: 3) menyimpulkan definisi filsafat berdasarkan watak dan fungsinya. Kesimpulan itu ialah (1) filsafat adalah sekumpulan sikap dan kepercayaan terhadap kehidupan dan alam yang biasanya diterima secara kritis (arti informal), (2) filsafat adalah suatu proses kritik atau pemikiran terhadap kepercayaan dan sikap yang sangat kita junjung tinggi (arti formal), (3) filsafat adalah usaha untuk mendapatkan gambaran keseluruhan. Artinya, filsafat berusaha untuk mengkombinasikan hasil bermacam-macam sains dan pengalaman kemanusiaan sehingga menjadi yang konsisten tentang alam (arti spekulatif), (4) filsafat adalah analisis logis dari bahasa serta penjelajahan tentang arti kata dan konsep. Corak filsafat yang demikian ini dinamakan juga logosentrisme, (5) filsafat adalah sekumpulan problem yang langsung yang mendapatkan perhatian dari manusia dan yang dicarikan jawabannya oleh ahli-ahli filsafat.

Tanpa menambahkan pengertian lain tentang filsafat, maka dapatlah kita mengerti bahwa filsafat itu merupakan bentuk berfikir, proses berfikir, dan hasil berfikir tentang Tuhan, alam, dan manusia. Oleh karena itu, semua pandangan diatas adalah benar adanya. Perbedaan definisi diatas hanya terletak pada sudut dimana filsafat itu dilihat dan ditarik pengertian.

\section{FILSAFAT DALAM KALANGAN AGAMA HINDU}

Tulisan-tulisan agama Hindu yang paling kuno praktis dapat disamakan dengan uraian tentang Brahmanisme, khusus dalam tulisantulisan Veda (sejak 1250 SM, madah-madah dan amsal-amsal) dan secara istimewa dalam Upanisad (750-500 SM) satu gagasan pokok tampil kemuka yakni eksistensi ditandai oleh penderitaan. Manusia dibelenggu oleh karma, daya kekuatan perbuatannya yang secara niscaya menghasilkan hadiah atau hukuman dalam eksistensi berikutnya (reinkarnasi). Tujuan hidup kita adalah mencapai pembebasan (moksa) dari roda karma itu: pembebasan tersebut tercapai lewat pengertian (Peursen, 1983: 106).

Pengertian tadi tidak hanya meliputi pengetahuan teoritis, tetapi menuntut dari manusia tapa brata yang keras, sehingga akhirnya ia menemukan "aku" sejati atau atman (semula berarti nafas). Itulah "aku" yang berdiri pada dirinya sendiri, lepas dari badan, lepas dari pikiran, perasaan dan kemauan, pokoknya yang tidak dapat dibatasi atau didefinisikan. Atman itu ternyata sama dengan hakekat kenyataan yang paling dalam dan paling tinggi, dasar purba dunia ini atau Brahman. Brahman itu (jangan disamakan dengan Brahma) memancarkan kesaktian, sehingga upacara-upacara Veda ada hasilnya. Pandangan metafisika ini bersumber pada praktek religius seperti diuraikan dalam tulisan-tulisan Veda (korban dan doa). Pembebasan tercapai, bila kita mengerti bahwa atman dan Brahman bersatu padu.

Oleh kalangan agama Hindu dikemudian hari dihasilkan juga sebuah tulisan religius 
yang dikenal dengan Bhagavadgita, yang tema pokoknya ialah bhakti, pasrah diri dengan penuh kepercayaan. Demikian juga kitab-kitab sutra (semacam amsal) beserta komentarnya memainkan peranan penting, khusus mengenai spekulasi-spekulasi filsafat. Barulah kemudian muncul mazhab-mazhab filsafat besar. Enam diantaranya berkembang terus dan menghasilkan tulisan-tulisan mendalam mengenai logika dan teori pengetahuan. Dua sistem yang paling terkenal disebut disini. Yang pertama adalah Sānhkya (ilmu tentang penalaran) dari abad I M. menurut sistem ini dasar purba yang menopang segala sesuatu bukan satu atau tunggal melainkan dua, yang satu bersifat material, yang lain spiritual/kejiwaan. Selain dualistis, sistem ini juga bersifat atheistis, walaupun mengakui adanya dewa-dewa, tetapi tidak menerima adanya satu mahadewa. Selain itu roh-roh dapat berpindah-pindah dari seorang manusia kepada seorang dewa dan sebaliknya.

Titik pangkal dalam alam pikiran Sānhkya ialah sebuah prinsip material, kodrat purba yang selalu bergerak aktif (prakrti). Prinsip ini melahirkan unsur-unsur material, tetapi juga bakat-bakat psikis seperti misalnya pikiran dan perasaan. Tahap-tahap perkembangan prakrti itu menampakan diri dalam suatu lingkaran abadi yang meliputi terjadinya dan binasanya dunia-dunia. Berhadapan dengan prakrti itu terdapat prinsip rohani yang pasif dan sadar diri (purusha). Inilah tempat asal-usulnya jiwajiwa yang berbeda dari bakat-bakat psikisnya. Barang siapa memahami dualisme hakiki ini telah mencapai tahap pembebasan. Kesadaran bahwa purusha tidak ada sangkut pautnya dengan prakrti menghapuskan dasar segala penderitaan. Ini juga membebaskan manusia dari dunia kebendaan karena kesadaran lalu lenyap dari prakrti dan dengan demikian lenyap pula segala pengalaman tentang penderitaan.

Sistem yang paling penting adalah Vedānta yang erat hubungannya dengan kitab-kitab suci agama Hindu sebagai sumber wahyu. Dalam sistem ini terdapat berbagai mazhab, diantaranya Shankara (+- 800) yang pengaruhnya sangat luas. Mazhab Shankara merupakan perpaduan dari berbagai sistem dan mengakibatkan suatu perkembangan baru dalam agama Hindu sehingga dapat memojokkan agama Buddha di India. Khususnya refleksi terhadap proses pengetahuan seperti dikembangkan oleh Shankara sangat menarik karena sifatnya yang rumit-rumit (subtil).

Menurut mazhab Shankara terdapat dua tingkatan dalam kebenaran. Bagi manusia yang percaya akan dunia pengalaman inderawikebenaran tingkat pertama-dunia ini memang ada, yaitu sebagai perpaduan prakrti dan purusha, kedua prinsip itu berasal dari ketuhanan tertinggi yang berpribadi. Diatas tangga kebenaran ini yang dapat disebut kebenaran realistis masih terdapat suatu kebenaran yang bersifat idealistis. Tahap ini tercapai oleh pengertian yang tidak berdasarkan pengamatan inderawi maupun penalaran akal budi, melainkan meditasi yang berakar dalam wahyu ilahi seperti diungkapkan dalam kitab-kitab Veda. Dunia yang dikenal pada tahap pertama tadi lalu Nampak sebagai semu atau maya dan manusia memperoleh pembebasan karena diri pribadinya yang paling dalam (atman) dipersatukan dengan dasar mutlak segala-galanya yang tidak berpribadi (Brahman).

Dewasa ini sistem Vedānta ini dapat dipandang sebagai filsafat Hindu yang resmi. 
Ahli-ahli pikir mistik dari abad ke -19, seperti Ramakrishna dan Vivekananda, sangat dipengaruhi olehnya. Khusus dalam bidang agama, demikian pandangan mereka, tahap kebenaran pertama dijabarkan oleh pendiri-pendiri agama-agama besar seperti Nabi Muhammad, Kristus dan Buddha. Masing-masing menampilkan suatu aspek daripada religi yang tunggal dan universal, yang bertumpu pada prinsip purba ilahi yang meliputi segala-galanya. Juga karya seorang ahli filsafat India dewasa ini, Sri Radhakrishnan, ditentukan oleh cakrawala religius tersebut.

\section{Dalam lingkungan alam pikiran} Hindu, filsafat tidak mempunyai kedudukan otonom. Memang, filsafat disana sangat mendalam menyelami dasar-dasar kenyataan dan pengetahuan, tetapi ini semua berkisar pada kehausan akan penebusan dan pelepasan. Titik tolak segala pemikiran ialah eksistensi itu sama dengan penderitaan. Tidak ada pemikiran bahwa eksistensi bercirikan kesalahan atau dosa. Hinduisme modern merusaha menyusun suatu sistem universal yang meliputi segala agama agama dan filsafat sebagai pancaran-pancaran kebenaran tunggal. Tetapi justru universalisme ini ditentukan oleh suatu cakrawala religius yang sangat khas (Peursen, 1983: 108).

\section{PEMIKIRAN KEFILSAFATAN PYTHAGORAS}

Pemikiran kefilsafatan Pythagoras memiliki kedudukan tersendiri dalam alam pikiran Yunani, sebab pemikirannya berdasarkan pada agama dan paham keragaman. Ia berasal dari Samos yang lahir kira-kira 580 sebelum Masehi. Selain sebagai penggagas filsafat bilangan,
Pythagoras juga dikenal baik sebagai penemu hukum geometri atau teorema yang berguna untuk menentukan panjang sisi miring dalam segitiga. Panjang sisi miring (hipotenusa) pada segitiga siku-siku menurut teorema Pythagoras ditentukan oleh perhitungan akar dari penjumlahan hasil kuadrat dari kedua sisi yang lain. Teorema yang sederhana ini berlaku umum dan menjadi dasar perkembangan geometri Non-Euclid. Teorema Pythagoras ini juga menjadi inspirasi awal baik bagi Einstein dalam menyusun teori relativitas umum maupun bagi seluruh fisika modern yang mencoba menyusun teori terpadu melalui manifestasi ruang-waktu geometri (Sumber: https://soniasworldd.wordpress.com/2014/04/19/ mengenal-tokoh-filsafat-klasik-phytagoras/).

Pythagoras mendirikan perkumpulan yang akhirnya menjadi sebuah terikat. Ujung terikat Pythagoras ialah mendidik kebatinan dengan menyucikan roh. Pythagoras percaya akan perpindahan jiwa dari makhluk yang sekarang kepada makhluk yang akan datang. Apabila seseorang meninggal, jiwanya kembali lagi kedunia, masuk kedalam badan salah satu hewan. Menurut suatu cerita, yang maksudnya barangkali mau menyindir, Pythagoras pada suatu hari sedang berjalan-jalan. Tampak olehnya seseorang sedang memukul anjing, sehingga anjing itu menjerit-menjerit. Lalu ia berkata: "Hai sanak, jangan dipukul anjing itu! Didalamnya ada jiwa seorang sahabatku, terdengar olehku dari jeritannya". Menurut kepercayaan Pythagoras, manusia itu asalnya Tuhan. Jiwa itu adalah penjelmaan daripada Tuhan yang jatuh kedunia karena berdosa. Dan ia akan kembali kelangit ke dalam lingkungan Tuhan bermula, apabila sudah dicuci dosanya itu. Hidup murni adalah 
jalan untuk menghapuskan dosanya itu. Tetapi kemurnian tidak tercapai sekaligus, melainkan berangsur-angsur. Sebab jiwa itu berulang-ulang turun ketubuh makhluk dahulu. Dengan jalan begitu, dari setingkat ke setingkat ia mencapai kemurnian. Untuk mencapai hidup murni, haruslah orang memantangkan makan daging dan kacang. Menurut kepercayaannya, sifat binatang yang buas hinggap di udara. Dengan kepercayaannya itu Pythagoras menjadi penganjur vegetarisme, memakan sayur mayur dan buah-buahan saja. Dalam ajarannya Pythagoras menegaskan bahwa hidup didunia merupakan persediaan untuk di akhirat. Apabila seseorang akan diterima menjadi anggota harus berdim diri selama lima tahun. Apabila tidak berhasil maka ia akan ditolak menjadi kawannya. Pemikiran Pythagoras disampaikan secara lisan, jadi ajarannya tidak tertulis. Akibatnya terjadi percampuran antara pemahaman murid dan ajaran gurunya. Dengan demikian sulit untuk dapat memastikan ajaran Pythagoras yang sebenarnya. Selain dari ahli mistik, Pythagoras tersebut juga sebagai ahli pikir. Terutama dalam ilmu matematika dan ilmu berhitung kesohor namanya. Banyak pengertian yang dalam-dalam berasal dari dia. Dialah yang mula-mula sekali mengemukakan teori dari hal angka-angka yang menjadi dasar ilmu ilmu berhitung. Dan karena dialah orang mendapat keinsafan bahwa berhitung itu bukan saja kecakapan menghitung seperti yang dikerjakan sehari-hari. Orang belajar matematika kebal akan segitiga Pythagoras. Kemudian ia pula mengajarkan, bahwa tinggi rendah bunyi biola berbanding dengan panjang pendek talinya.

Tetapi tidak saja pada benda perbandingan itu dinyatakan oleh angka-angka, juga dalam lapangan alam. Dan dari ilmu matematika Pythagoras melompat kedalam dunia pandangan.
Alam ini katanya, tersusun sebagai angkaangka. Dimana ada matematik, ada susunan, ada kesejahteraan. Bintang yang banyak dilangit menyatakan kedudukan yang teratur, kesejahteraan yang sebesar-besarnya. Bendabenda dilangit itu mempunyai gerak yang tertentu dan mempunyai edaran yang pasti, menurut irama yang tetap. Sebab itu Pythagoras suka berkata tentang "kesejahteraan di langit". Mana yang bergerak, berbunyi. Sebab dilangit itu ada bunyi, ditimbulkan oleh gerakan bintang-bintang. Tinggi rendah bunyi lagu yang sejahtera di langit itu karena ia sudah biasa dengan itu sejak lahirnya. Tetapi tidak di alam saja berkuasa matematik. Ia juga berkuasa dalam segala barang. Dengan jalan ini Pythagoras sampai ke pokok ajarannya yang mengatakan bahwa "segala adalah angka-angka". Demikianlah pengaruh matematika atas dirinya dan pandangannya, sehingga pada segala barang ia melihat angka-angka. Tidak lain dari angka-angka yang tampak olehnya. Dan oleh karena mistik yang dibawakan ke angka-angka tadi, ia terjerumus ke dalam dunia fantasi, dengan meletakkan berbagai paham yang ajaib pada angka-angka itu. Pemikiran Pythagoras dituliskan oleh Philolaos. Menurut philolaos tanda kebenaran adalah angka. Menurut gurunya (Pythagoras) angka genap dan ganjil berbeda. Angka ganjil menentukan dan angka genap tidak terhingga. Benda-benda di dunia ini tersusun dari yang genap dan yang ganjil (Sudarsono, 2001: 27-29).

\section{PANDANGAN HINDU TERHADAP PEMI- KIRAN KEFILSAFATAN PYTHAGORAS}

Bila ditelaah secara mendalam, khususnya bagi yang sudah mempelajari konsep-konsep tentang agama Hindu, tentunya akan berfikir 
mungkinkah pemikiran Pythagoras dipengaruhi oleh ajaran Veda?. Penulis sendiri tidak berani memastikan hal tersebut karena masih dalam keterbatasan referensi tertulis.

Dari sudut pandang ajaran agama Hindu, sudah tentu ada sebuah kemiripan konsep pemikiran antara Pythagoras dan Hindu. sebut saja yang pertama bahwa Pythagoras percaya akan adanya Jiwa dan perpindahan jiwa dari makhluk yang sekarang kepada makhluk yang akan datang. Apabila seseorang meninggal, jiwanya kembali lagi kedunia, masuk kedalam badan salah satu hewan. Hindu sendiri mengenal ajaran tersebut sebagai Punarbhawa atau Samsara yang merupakan bagian dari Panca Sraddha.

Jiwa/roh/atma merupakan percikan terkecil dari Tuhan yang merupakan salah satu bagian dari Panca Sraddha yaitu Atma Sraddha. Dalam fungsinya, jiwa tersebut berfungsi untuk menghidupkan unsur badan jasmaniah makhluk hidup atau dapat dikatakan bahwa unsur material harus disatukan dengan unsur kejiwaan agar menimbulkan aktivitas kehidupan (karma). Ketika terjadi sebuah kematian pada makhluk hidup, jiwa atau roh tidak selamanya akan tinggal di neraka ataupun di sorga. Ia lahir lagi ke dunia ini (punarbhawa/samsara/lingkaran kelahiran). Bagaimana kelahiran tergantung pada karmawasananya. Kalau ia membawa karma baik, lahirlah ia menjadi orang yang berbahagia, berbadan sehat dan berhasil cita-citanya. Sebaliknya bila ia membawa karma yang buruk ia akan lahir menjadi orang yang menderita. Kelahiran kembali ini adalah kesempatan untuk memperbaiki diri (Tim, 1994: 58). Hal tersebut juga dijelaskan dalam sloka Sarasamuccaya, 6:
Paramarthanya, pengpengen ta pwa katemwaniking si dadi wwang, durlabha wiya ta, sākşāt handaning mara ring swarga ika, sanimittaning tan tiba muwah ta pwa damelakena

Terjemahan :

Pergunakanlah dengan sebaik-baiknya kesempatan menjadi manusia, kesempatan yang sungguh sulit diperoleh, yang merupakan tangga untuk datang menuju sorga. Segala sesuatu yang menyebabkan agar tidak jatuh lagi itulah hendaknya dilakukan (Kajeng,dkk, 2010: 10)

Di sisi lain, Pythagoras juga menyatakan bahwa untuk mencapai hidup murni, haruslah orang memantangkan makan daging dan kacang. Menurut kepercayaannya, sifat binatang yang buas hinggap di udara. Dengan kepercayaannya itu Pythagoras menjadi penganjur vegetarisme, memakan sayur mayur dan buah-buahan saja.

Vegetarian menurut pengertian yang diberikan oleh C.W Leadbeater dalam Darmayasa (1997: 3) adalah: hidup yang berpantang terhadap segala makanan yang berasal dari atau diperoleh dengan jalan penyembelihan binatang-binatang, termasuk juga jenis burung-burung dan jenis ikan-ikanan. Vegetarian menurut sumber lain mengatakan berasal dari kata latin vegetare yang berarti saňjiwani atau amerta penghidup. Memang vegetarian bisa memberikan hidup yang baru kepada seseorang. Sumber lain lagi mengatakan vegetarian berasal dari kata latin vegetabilis. Adapun vegetarian ini dibedakan atas tiga bagian yaitu: 
1. Lacto-ovo Vegetarian: golongan ini perkecualiannya telor (membolehkan makan telor)

2. Lacto Vegetarian: golongan ini tidak memakan telor

3. Vegan; dua golongan diatas membolehkan minum susu, tetapi golongan vegan ini tidak membolehkan alias menolak minum susu.

Lebih jauh hidup vegetarian ini, yang secara gamblang dijelaskan oleh C.W Leadbeater dalam Darmayasa (1997: 4) dalam bukunya yang sangat laris dan telah dicetak berulang-ulang "Sayuranisme/Vegetarian dan Ilmu Kerohanian/ Occultisme. Dalam bukunya ini nyata sekali dibahas keunggulan berpantang makan daging dibandingkan dengan makan daging. Dibuktikan secara jelas dengan beberapa keuntungan yaitu :

1. Makanan vegetarian lebih banyak mengandung zat makanan

2. Makanan vegetarian mengurangi penyakit

3. Makanan vegetarian lebih bersifat alamiah bagi manusia

4. Makanan vegetarian menambah daya kekuatan yang semakin besar

5. Makanan vegetarian menyebabkan berkurang nafsu kebinatangan

6. Makanan vegetarian lebih bersifat penghematan

Dalam sudut pandang agama Hindu, kitab suci Veda menganjurkan agar kita mengendalikan indria-indria, sebab indria-indria memiliki dorongan-dorongan yang sangat kuat itu yang paling sulit dikendalikan adalah lidah, perut dan dorongan kemaluan (jihva-vegam udaropasthavegam). Ketiga ini merupakan satu garis lurus. Diantara ketiga ini lidah adalah akarnya, lidahlah yang paling sulit dikendalikan. Karena lidah kurang dikendalikan seorang gampang berada dalam kebingungan, kegelapan, hawa nafsu kelamin selalu mengganggu dan lain-lain. lidah adalah akar dari pohon penderitaan dalam diri manusia (Darmayasa, 1997: 23).

Menurut Darmayasa (1997: 24) Dalam lontar-lontar warisan leluhur kita juga diajarkan berbagai jenis brata yang tanpa daging. Hal ini dimaksudkan sebagai ajakan secara halus untuk mengendalikan lidah dengan cara mempraktekkan ahimsa dan hidup vegetarian. Pengaturan makanan yang baik memungkinkan orang untuk sukses dalam yoga atau kerohanian. Lontar Aji Brata menjelaskan pengendalian lidah khususnya secara panjang lebar dan dengan berbagai tapasya. Ada disebut Brata Nyaraswati, yaitu makan tumpeng nasi tanpa daging. Manfaat dari brata ini adalah segala sifat baik bisa datang, berhasil segala citacita dan rukun dalam berumah tangga. Dewi yang dipuja adalah Bhatari Raja Lakşmī dengan mantranya : Om śri raja lakşmiya namah. (mantra yang tepat adalah Om śri rāja-laksmyai namah.

Brata-brata lain yang tanpa daging antara lain : Brata Mupasada, Brata Prāna (pantang makan segala yang berjiwa atau binatang), Brata Nutaken Wulan, Brata Patrahara (hanya makan daun-daunan), Brata Phalahara (hanya makan buah-buahan, Brata Misa (pantang makan babi, sapi, kerbau, dsb), Brata Kanakadrawa, Brata Mangan Sārwa Wija, Brata Tri Samana, Brata Eka Bakta, Brata Ngadite, Brata Mandawa, Brata Sang Bima, Brata Mangan Pitung Kepel, Brata 
Nutaken Puspa Bhatara Gana, Brata Sanini Graha, dan lain-lain

Ada pula dijelaskan dalam lontar initentang Brata Ekādaśi yang sangat tekun diikuti oleh para Vaisnava termasuk oleh Mahātmā Gandhi. Perhitungan secara sederhana dapat dilakukan seperti ini; setiap hari kesebelas atau empat hari sebelum purnama dan empat hari sebelum tilem berpuasa penuh. Kalau tidak bisa berpuasa penuh boleh makan sebagaimana biasa kecuali makanan yang berasal dari beras, tepung-tepungan, kacangkacangan. Manfaat yang diperoleh dari brata ini adalah sampai di alam rohani setelah meninggal atau lahir menjadi raja śakti (Darmayasa, 1997: 24).

Ajaran ahimsa (termasuk vegetarian) juga dijelaskan dalam lontar Maheśwari Śāstra. Lontar ini menjelaskan antara lain bahwa jika ahimsa tidak dipertahankan dapat menyebabkan kemarahan, kebingungan, kemabukan, iri hati, pikiran kacau dan hawa nafsu bertumbuhan : Apan yan tan karaksang ahimsā brata, makanimita krodha, moha, mana, mada, mātsarya, nguniunin makanimitang kāma, yeka panten dadyanya (Maheśwari Śastra 2b). Yang lain yang dianjurkan tidak boleh dimakan, terlebih-lebih oleh pendeta adalah babi, ayam, kera, monyet, tekukur, tupai, kodok, binatang berbisa, anjing, rase, atat, suing, jalak (bisa bicaraa seperti manusia), dan banyak jenis burung-burung dilarang, segala binatang berkuku lima juga dilarang dimakan (Darmayasa, 1997: 280).

Sejak jaman bahari rsi-rsi dan para pendeta tidak pernah bergaul dengan daging. Beliau melihat makanan jenis daging yang diolah sedemikian rupa tidaklah ada bedanya dengan seekor bangkai anjing dijalanan. Sanyasi-sanyasi, para Gosvami dan guru-guru suci selalu tidak pernah kena daging, oleh karena beliau sudah mengerti dengan sepenuhnya apa yang benar dan apa yang tidak benar, apa yang menguntungkan dan apa yang tidak menguntungkan, apa yang perlu dan apa yang tidak perlu. Beliau mengerti hal-hal seperti ini atas petunjuk-petunjuk dari gurunya dan berdasarkan apa yang ditemukan dalam kitab suci. dalam hal ini ada yang perlu diselipkan suatu pendapat yang mengatakan bahwa di dalam kitab suci ini, di dalam kitab suci itu, perihal makan daging ini adalah dibenarkan. Tetapi, bagi mereka yang hendak menyucikan diri, kitab suci menganjurkan cara-cara yang lebih murni lagi. Inilah keluwesan kitab suci Veda. Semua diberi jalan sesuai dengan tingkat keinsafan masing-masing. Khususnya menurut tingkat Tri Guna. Bagi mereka yang serius mendalami kitab suci akan mengerti yang sebenarnya bahwa makanan ada tiga golongan dan sesuai dengan sifatnya orang memilih makanan untuk dirinya (āhārastvapi sarvasya tri-vidho bhavati priyah). Seperti dijelaskan dalam pustaka suci Śrimad Bhagavadgītā, bahwa makanan diklasifikasikan menjadi tiga kelas yaitu :

1. Makanan jenis Sattvam (makanan dalam kebaikan)

2. Makanan jenis rajas (makanan dalam kenafsuan)

3. Makanan jenis tamas (makanan dalam sifat kebodohan, kegelapan)

Jenis makanan yang mana kita makan setiap hari, jenis sifat itulah yang dominan dalam diri seseorang. Sifat-sifat yang dimiliki seseorang tidaklah suatu kebetulan, ini sangat tergantung dari jenis makanan yang ia makan. Memang makanan 
amat penting bagi kita, tetapi makanan sattvika adalah pilihan terbaik. Demikian pentingnya pengaturan makanan bagi pembentukan sifat dan karakter seseorang (Darmayasa, 1997: 36).

Jadi jelaslah sudah bahwa pemikiran kefilsafatan Pythagoras ada unsur kemiripan dengan konsep ajaran Hindu utamanya tentang eksistensi jiwa dan perpindahannya dari satu makhluk ke makhluk yang lainnya melalui proses kelahiran berulang-ulang (Punarbhawa) serta ajaran Ahimsa utamanya tentang anjuran untuk menjadi penganut vegetarian guna mewujudkan kesehatan jasmani dan meningkatkan kemurnian jiwa. Dari sudut pandang agama Hindu, pendapat Pythagoras tersebut tidak bertentangan dengan kaidah-kaidah keagamaan malahan pendapatnya tersebut semakin mengukuhkan ajaran Hindu secara universal.

\section{PENUTUP}

PemikirankefilsafatanPythagorasmemiliki kedudukan tersendiri dalam alam pikiran Yunani, sebab pemikirannya berdasarkan pada agama dan paham keragaman. Ujung terikat Pythagoras ialah mendidik kebatinan dengan menyucikan roh. Pythagoras percaya akan perpindahan jiwa dari makhluk yang sekarang kepada makhluk yang akan datang. Untuk mencapai hidup murni, haruslah orang memantangkan makan daging dan kacang. Menurut kepercayaannya, sifat binatang yang buas hinggap di udara. Dengan kepercayaannya itu Pythagoras menjadi penganjur vegetarisme, memakan sayur mayur dan buah-buahan saja.

$$
\text { Pemikiran kefilsafatan Pythagoras }
$$

ada unsur kemiripan dengan konsep ajaran
Hindu utamanya tentang eksistensi jiwa dan perpindahannya dari satu makhluk ke makhluk yang lainnya melalui proses kelahiran berulangulang (Punarbhawa) serta ajaran Ahimsa utamanya tentang anjuran untuk menjadi penganut vegetarian guna mewujudkan kesehatan jasmani dan meningkatkan kemurnian jiwa. Dari sudut pandang agama Hindu, pendapat Pythagoras tersebut tidak bertentangan dengan kaidah-kaidah keagamaan malahan pendapatnya tersebut semakin mengukuhkan ajaran Hindu secara universal.

\section{DAFTAR PUSTAKA}

Banasuru, Aripin. Filsafat Dan Filsafat Ilmu, Dari Hakikat Ke Tanggung Jawab. Bandung : Alfabeta.

Tim. 2003. Intisari Ajaran Hindu. Surabaya: Paramita.

Darmayasa. 1997. Ahimsa Dharma \& Vegetarian Surabaya: Paramita.

Tim. 1994. Buku Pelajaran Agama Hindu Untuk Perguruan Tinggi. Jakarta: Hanuman Sakti.

Sudarsono. 2001. Ilmu Filsafat Suatu Pengantar. Jakarta: Rineka Cipta.

Kajeng, I Nyoman, dkk. 2010. Sarasamuccaya. Surabaya : Paramita.

Peursen, C.A. van. 1983. Orientasi Di Alam Filsafat. Jakarta: Gramedia.

Sumawa, I wayan, dan Krisna, Tjokorda Raka. Modul Darsana. Jakarta: Dirjen Bimas Hindu dan Buddha. 
Susanto, A. 2013. Filsafat Ilmu, Suatu Kajian Dalam Dimensi Ontologis, Epistemologis, Dan Aksiologis. Jakarta: Bumi Aksara.

Tim. 2005. Kamus Istilah Agama Hindu. Denpasar: Kantor Wilayah Departemen Agama Provinsi Bali.

www.wisdoms4all.com/Indonesia

http://sites.google.com/site/afrizalmansur/ filsafat-agama

https://soniasworldd.wordpress.com/2014/04/19/ mengenal-tokoh-filsafat-klasikphytagoras/ 